\title{
Produtos alternativos no controle do oídio em mudas de eucalipto
}

\author{
R afaela M azur Bizi ${ }^{1}$, A lbino Grigoletti J unior ${ }^{2}$, Celso Garcia A uer ${ }^{2}$, L ouise L arissa M ay-De M io ${ }^{1}$
}

${ }^{1}$ U niversidade Federal do Paraná, D epartamento de Fitotecnia e Fitossanitarismo, 80035-050, Curitiba-PR; ${ }^{2}$ E mbrapa Florestas, Colombo-PR

* Parte da dissertação da primeira autora, bolsista do CN Pq, projeto 472297/2003-1.

A utor para correspondência: C elso Garcia A uer

Data de chegada: 15/08/2006. A ceito para publicação em: 08/01/2008

\section{RESUMO}

Bizi, R.M.; Grigoletti J unior, A.; A uer, C.G.; M ay de M io, L. L. Produtos alternativos no controle do oídio em mudas de eucalipto. Summa Phytopathologica, v.34, n.2, p.144-148, 2008

A silvicultura brasileira tem empregado o eucalipto pela sua adaptabilidade, rápido crescimento e produtividade, além de possuir outras características como a qualidade, diversidade e adequação de sua madeira para a indústria. Para tal, existe a necessidade de uma produção contínua de mudas, as quais podem ser atacadas pelo fungo Oidium sp. 0 controle do oídio é feito com fungicidas, mesmo não havendo produtos registrados para o eucalipto. 0 objetivo deste trabalho foi avaliar produtos alternativos (sais e tanino, óleos, extratos de plantas, leite e derivados, e antagonistas) para o controle desta doença comparando os mais promissores com fungicida. Os produtos foram pulverizados em mudas de Eucalyptus benthamii Maiden \& Cambage e mantidas em casa-de-vegetação com al to potencial de inóculo de Oidium sp. A severidade da doença foi avaliada por meio de uma escala de notas de 0 (ausência de sintomas) a 4 (sintomas muito severo) e calculada a área abaixo da curva de progresso da doença (AACPD). Verificou-se que, os menores valores de AACPD de oídio foram obtidos com piraclostrobina + epoxiconazol, que controlou $92 \%$ da doença, e os melhores produtos alternativos testados foram o leite de vaca e Lecanicillium sp. que controlaram respectivamente $36,5 \%$ e $33,9 \%$ da doença no ensaio comparativo.

Palavras-chave adicionais: controle alternativo, E ucalyptus benthamii, 0 idium sp.

\section{ABSTRACT}

Bizi, R.M .; Grigoletti J unior, A.; A uer, C.G.; M ay-De M io, L. L. A Iternative products to control powdery mildew on eucalyptus seedlings. Summa Phytopathologica, v.34, n.2, p.144-148, 2008

Eucalypt plays an important role in Brazilian forestry because of its good adaptation, fast growth, high productivity, as well as a lot of good qualities for industry. Eucalyptus reforestation needs a continuous production of seedlings, which can be attacked by Oidium sp. The control of powdery mildew is based on fungicides, but for eucalypts there are no products commercially registered. The objective of this work was to evaluate chemical products, essential oils, plants extracts, milk and dairy products and antagonist for the alternative control of this disease. Seedlings of E. benthamii Maiden \& Cambage were used in the assays. Disease severity was assessed using a scale varying from 0 (no symptoms) to 4 (severe symptoms) and calculated the area under progress disease curve (AUDPC). It was verified that the lowest AUDPC values of powdery mildew were obtained with piraclostrobin + epoxyconazol, and cow milk and Lecanicillium sp. were the best alternative products.

A dditional keywords: al ternative control, Eucalyptus benthamii, O idium sp.

A cultura do eucalipto no B rasil tem sido destinada à produção de madeira para a indústria de papel e celulose e de carvão vegetal. A adequação de sua madeira para fins industriais, o rápido crescimento e a el evada produção de sementes são fatores que alavancaram a contínua expansão do setor florestal brasileiro, baseado em plantações com eucaliptos $(12,18)$.

A s doenças podem causar perdas econômicas desde a fase de viveiro até os plantios adultos. Dentre as principais doenças fúngicas do eucalipto destaca-se o oídio, causado por O idium sp. (14). Essa doença é freqüente e não existem estudos completos para estimar os prejuízos causados e principalmente os métodos de controle. 0 agravamento dos problemas fitossanitários em viveiros florestais pode ser decorrente de um manejo inadequado ou do uso incorreto das medi das de controle. 0 patógeno está disseminado nas regiões Sul e Sudeste, de importância local izada e sazonal. No Paraná, tem-se verificado a sua ocorrência em árvores jovens e em mudas, desde o fim do verão até a primavera, quando há predominância de temperaturas amenas e baixa umidade relativa. Em casa-de-vegetação, os sintomas têm sido mais severos (2). 0 oídio pode causar perdas significantes quando não é controlado adequadamente (8). 
0 controle desta doença em viveiros de eucaliptos é feito com os mesmos fungicidas recomendados para outras plantas, mesmo não sendo registrados. A possibilidade dos fungici das causarem danos ao ambientee ao homem tem estimulado a redução do controle químico e o aumento do uso de outras medidas como o controle cultural, o controle biológico, 0 genético e o controle com produtos al ternativos (9).

Considerando-se a constante demanda por parte de viveiristas por recomendações de controle do oídio e a falta de produtos registrados, o objetivo deste trabal ho foi avaliar produtos al ternativos para o seu controle.

\section{MATERIAL E MÉTODOS}

Mudas de Eucalyptus benthamii Maiden \& Cambage, espécie suscetível ao oídio, foram produzidas a partir de semente em tubetes contendo uma mistura de substrato à base de casca de pínus suplementado com $800 \mathrm{~g}$ de N PK 8-28-16 mais $400 \mathrm{~g}$ de super fosfato simples, para $100 \mathrm{Kg}$ de substrato. A pós a formação do segundo par de folhas, fez-se o desbaste deixando-se a plântula mais vigorosa em cada tubete. A partir deste estádio as mudas foram consideradas aptas para o início dos ensaios, que se desenvolveram entre março de 2004 a janeiro de 2006.

Cinco grupos de produtos foram testados para a seleção dos mais eficientes: 1) sais e tanino; 2) óleos; 3) extratos de plantas; 4) leite e derivados e 5) antagonistas. Os produtos foram aplicados usando-se um pulverizador manual. Nas suspensões de antagonistas, foi adicionado um espalhante adesivo à base de polisorbato a $1 \%$ e para os demais produtos foi utilizado um espal hante à base de polioxietileno a $1 \%$. Nas plantas testemunhas, aplicou-se apenas água destilada esterilizada.

A pós 24 horas da primeira aplicação, as mudas foram mantidas em casa-de-vegetação com alto potencial de inóculo. Para tanto, mudas de $\mathrm{E}$. benthamii doentes eram mantidas na casa-de-vegetação para a manutenção do inóculo. 0 método de inoculação empregado foi modificado de Bettiol \& A stiarraga (5), pelo qual as mudas tratadas foram intercaladas com mudas doentes para serem infectadas naturalmente. Para eliminar um possível efeito de local, a cada dois dias cada caixa de mudas foi transferida de lugar, de modo que ao final do experimento todas tivessem passado pelos mesmos locais.

A avaliação consistiu da quantificação da severidade da doença utilizando-se a escal a de severidade para oídio proposta por Paz L ima et al. (11) e que foi adaptada para o eucalipto, conforme segue: $0=$ sem sintomas; 1 = infecção leve (presença do micélio do fungo nas fol has, sem esporulação); 2 =infecção média (esporulação sobre menos de $50 \%$ da muda); 3 = infecção severa (esporulação sobre mais de 50 $\%$ da muda); e 4 = infecção muito severa (cobertura total da muda, deformação da folha, necrose, enrolamento do primeiro par de folhas e queda das folhas).

A partir da entrada das mudas tratadas na casa-de-vegetação para a inocul ação natural foram realizadas as aplicações semanais. O s ensaios tiveram a duração de cinco semanas, com avaliações semanais da severidade da doença.

\section{Sais e tanino}

Foram empregados os seguintes produtos: metabissulfito de sódio $(0,4 \mathrm{~g})$; fosfito de potássio $(0,6 \mathrm{~mL})$; fosfito de cobre $(0,2 \mathrm{~mL})$; carbonato de cálcio $(2 \mathrm{~g})$; tanino $(2 \mathrm{~g})$; ácido acético $(1,2 \mathrm{~mL})$, bicarbonato de sódio $(0,4 \mathrm{~g})$; ácido bórico ( $1 \mathrm{~g})$; ácido ascórbico (1 g) e permanganato de potássio $(0,15 \mathrm{~g})$, cada diluído em $200 \mathrm{~mL}$ de água destilada.
Óleos

Foram empregados os óleos comerciais de pínus (produzido a partir de P inus spp.) e de dois tipos de eucalipto. U m deles produzido a partir de Corymbia citriodora (Hook.) K. D. Hill \& L. A. S. J ohnson e o outro de E. globulus Labill. Os óleos foram pulverizados na concentração de 1 \%, ao 1, 7, 14, 21 e 28 dias após a transferência para a casa-de-vegetação.

\section{Extratos de plantas}

Para a obtenção dos extratos brutos, plantas foram coletadas e selecionadas folhas jovens e brotações de plantas sadias. U ma quantidade de $100 \mathrm{~g}$ de folhas frescas de cada planta foi pesada e triturada com $1 \mathrm{~L}$ de água destilada esterilizada por $3 \mathrm{~min}$., depois peneirada e, em seguida, mantida em geladeira. Foram testados os extratos de alfavaca (0 cimum gratissimum L.), manjericão ( 0 . basilicum L.), ginkgo ( $G$ inkgo biloba L.), hortelã (M entha $x$ villosa Huds.) e eucalipto (E. globulus e $C$. citriodora). As pulverizações foram realizadas aos 6, 13, 20, 27 e 34 dias, após a transferência para a casa-de-vegetação.

\section{L eite e derivados}

N esse ensaio, utilizou-se o leite fresco de vaca na concentração de $20 \%$. 0 iogurte natural, a coal hada e o leitefermentado com lactobacil os foram empregados a $10 \%$. Todos os tratamentos foram diluídos em água e preparados no dia das aplicações. A s pulverizações foram feitas ao 1, 7, 14, 21 e 28 dias, após a transferência para a casa-de-vegetação.

\section{Antagonistas}

Foram utilizados os isolados: Lecanicillium sp. (Turfal), Bacillus subtilis (E mbrapa M eio A mbiente), Trichoderma viride Pers. ex Fr. e Clonostachys rosea (Link:Fr.) Schroers (E mbrapa U va e Vinho) e Saccharomyces cerevisiae M eyen ex Hansen (fermento biológico fresco comercial). A multiplicação dos quatro primeiros antagonistas foi através de repicagens em meio BDA para a obtenção de conídios. No caso do S. cer evisiae não houve multiplicação e somente preparo da solução a partir de produto comercial fresco. Os antagonistas foram pulverizados na concentração de $10^{7}$ ufc ou esporos $/ \mathrm{mL}$ ao $1,4,8,15,21$ e 28 dias após a transferência das plantas para a casa-de-vegetação.

\section{Compar ativo entre produtos}

Os tratamentos mais eficientes de cada grupo de produtos anteriormente testados foram comparados em um único ensaio para a seleção dos melhores produtos al ternati vos contra o oídio. U tilizouse a mesma metodologia de instalação, condução e avaliação dos ensaios anteriores. A s aplicações dos produtos foram ao 1, 6, 8, $11,13,18,22$ e 27 dias, com sete avaliações, em 2005. Neste ensaio foram preparadas duas testemunhas, uma com água destilada e a outra à base de piraclostrobina + epoxiconazol, determinado em um estudo anterior (7) como o mais eficiente contra o oídio do eucalipto e que foi utilizado como padrão de controle da doença.

Os dados de severidade da doença foram anal isados segundo os M odelos Lineares Generalizados, em delineamento inteiramente casualizado. Para selecionar os melhores tratamentos, as médias foram comparadas pelo teste de Tukey $(p<0,05)$. Nos ensaios com extratos de plantas foram utilizadas 30 mudas por tratamento e 20 mudas por tratamento nos demais grupos. Esta redução foi devido à dificuldade na obtenção de mudas sadias. Finalmente, no ensaio comparativo de diferentes produtos, foram utilizadas 40 mudas por tratamento para ter-se um maior número de repetições. 
Cada muda correspondeu a uma parcela. Com os dados de severidade foi calculado o percentual de controle da doença. No ensaio comparativo entre os produtos mais eficientes, fez-se o cál culo da área abaixo da curva de progresso da doença (A A CPD) e a análise estatística dos valores médios da A A CPD para cada tratamento, pelo teste de Tukey $(p<0,05)$.

\section{RESULTADOS E DISCUSSÃO}

As mudas mantidas na casa-de-vegetação foram naturalmente inoculadas, após os tratamentos aplicados sobre essas. A s mudas não tratadas (testemunha) foram as que apresentaram os sintomas típicos da doença de colonização da superfície foliar pelo micélio, seguido da esporulação intensa criando um aspecto pulverulento. As colônias iniciam-se nas folhas mais jovens e com o crescimento das mudas, observa-se a colonização e esporulação quando se tornam completamente expandidas. A I gumas folhas colonizadas pel o patógeno ficam enroladas ou em forma de canoa.

A doença foi controlada com alguns dos produtos testados, enquanto que al guns não controlaram o patógeno e outros causaram sintomas de fitotoxidez nas fol has. A severidade observada nas mudas do tratamento testemunha variou de acordo com a época em que foi montado 0 ensaio.

\section{Sais e tanino}

N enhum dos produtos testados diferiu significativamente da testemunha em relação à severidade da doença (Tabela 1). Somente 0 carbonato de cál cio e o tanino apresentaram as severidades médias da doença menores que o valor da testemunha.

Tanino, carbonato e metabissulfito foram considerados eficientes para o controle do oídio $(6 ; 10 ; 13)$, mas estes resultados não foram confirmados neste ensaio. A ineficiência destes produtos pode estar relacionada à sensibilidade das mudas de $\mathrm{E}$. benthamii a estes produtos. I nicial mente, houve fitotoxidez quando se aplicou a dose recomendada para o controle desta doença. Para contornar este problema foram testadas doses mais baixas até o desaparecimento da fitoxidez nas mudas, tornando os produtos menos eficientes. Portanto, nenhum destes produtos foi considerado adequado contra o oídio.

\section{Óleos}

O sóleos são ótimos agentes antimicrobianos, protegendo as plantas de bactérias e fungos fitopatogênicos e podem ser usados no controle al ternativo de doenças em plantas $(16,19)$. Entretanto, este potencial também não foi observado para controle do oídio em $E$. benthamii.

$\mathrm{N}$ ão houve diferenças significativas nos tratamentos ou menor severidade da doença em relação à testemunha e, portanto, nenhum óleo foi considerado eficiente. Possivel mente, os compostos orgânicos presentes nos óleos provocaram uma melhor fixação do patógeno nas folhas ou estimularam a germinação dos conídios e a colonização das folhas.

\section{Extratos de plantas}

Os extratos brutos de 0 . gratissimum, 0 . basilicum e $C$. citriodora têm apresentado potencial no controle de fitopatógenos (17). Entretanto, estes resultados não foram confirmados neste ensaio, onde a severidade do oídio após a aplicação do extrato de 0 . basilicum $(1,87)$ não diferiu estatisticamente da testemunha $(2,07)$. Os demais extratos testados apresentaram severidade superior ao da testemunha. Assim, nenhum extrato de planta foi eficiente contra o oídio.

U m dos fatores que pode ter contribuído para a falta de eficiência desses extratos, tal como no caso dos óleos, foi a presença de substâncias no extrato bruto que estimularam o patógeno e aumentaram a severidade da doença.

\section{L eite e derivados}

Todos os tratamentos utilizados diferiram estatisticamente da testemunha. 0 leite de vaca $(2,10)$ e o iogurte $(2,15)$ não diferiram estatisticamente entre si e apresentaram os menores valores de severidade em relação à testemunha $(3,75)$. Como o leite de vaca promoveu o maior valor de controle (44\%), este produto foi selecionado como eficiente.

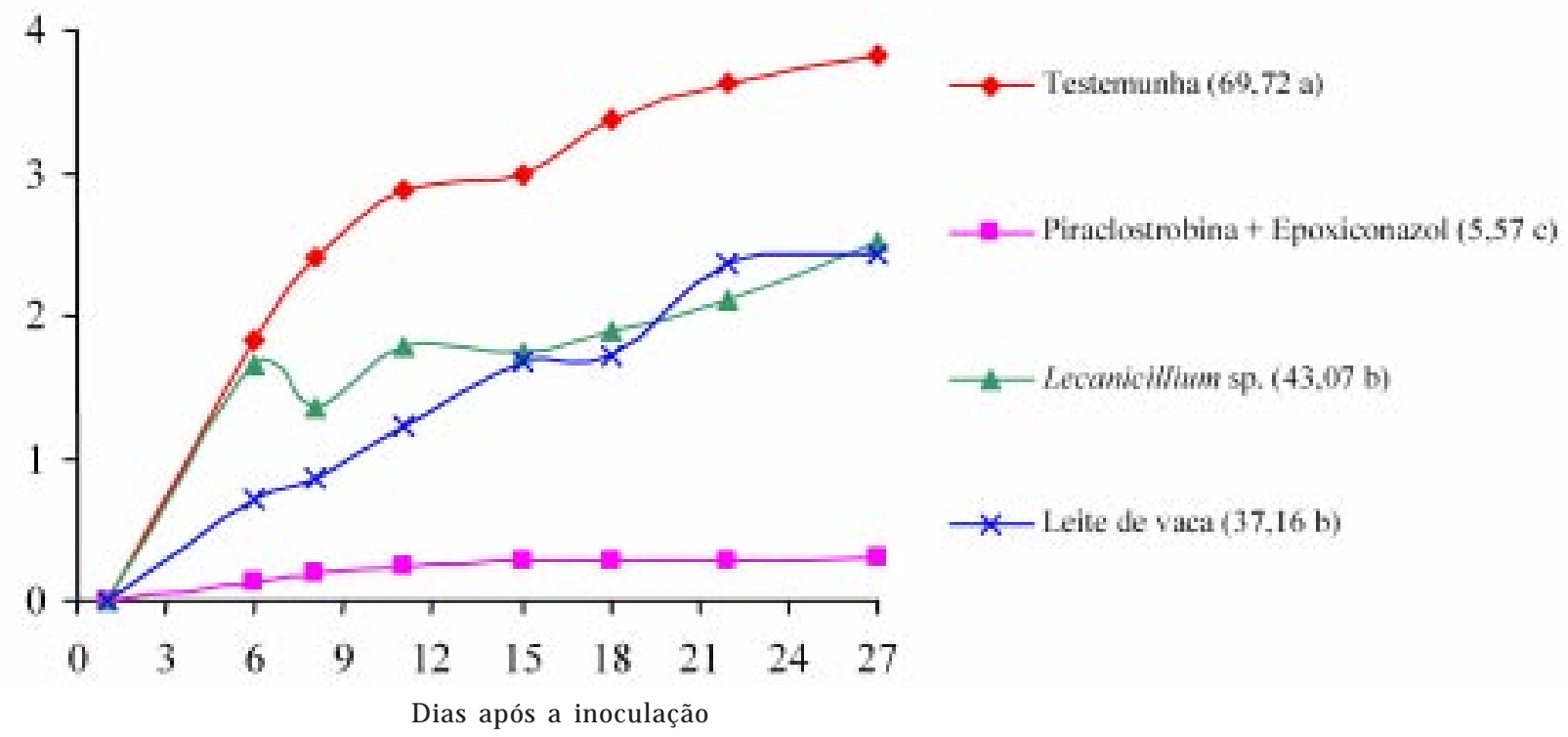

Figura 1. Curva do progresso da severidade do oídio em mudas de Eucalyptus benthamii tratadas com os produtos selecionados em testes preliminares. Colombo, PR, 2005. Severidade: 0 - ausência de sintomas a 4 - infecção muito severa. Valores entre parênteses na legenda representam a área abaixo da curva do progresso da doença (AACPD), média de 40 mudas (repetições) após 27 dias da inoculação natural com 0 idium sp. M édias seguidas pela mesma letra não diferem entre si pelo teste de Tukey ao nível de $5 \%$ de probabilidade.

$\mathrm{CV}=28,1 \%$. 
Tabela 1. Severidade final média após 34 dias da inoculação natural do oídio (0idium sp.) em mudas de eucaliptos (Eucalyptus benthamii) tratadas com sais e tanino, óleos, extratos de plantas, leite e derivados e antagonistas. Colombo, PR, 2004-2005.

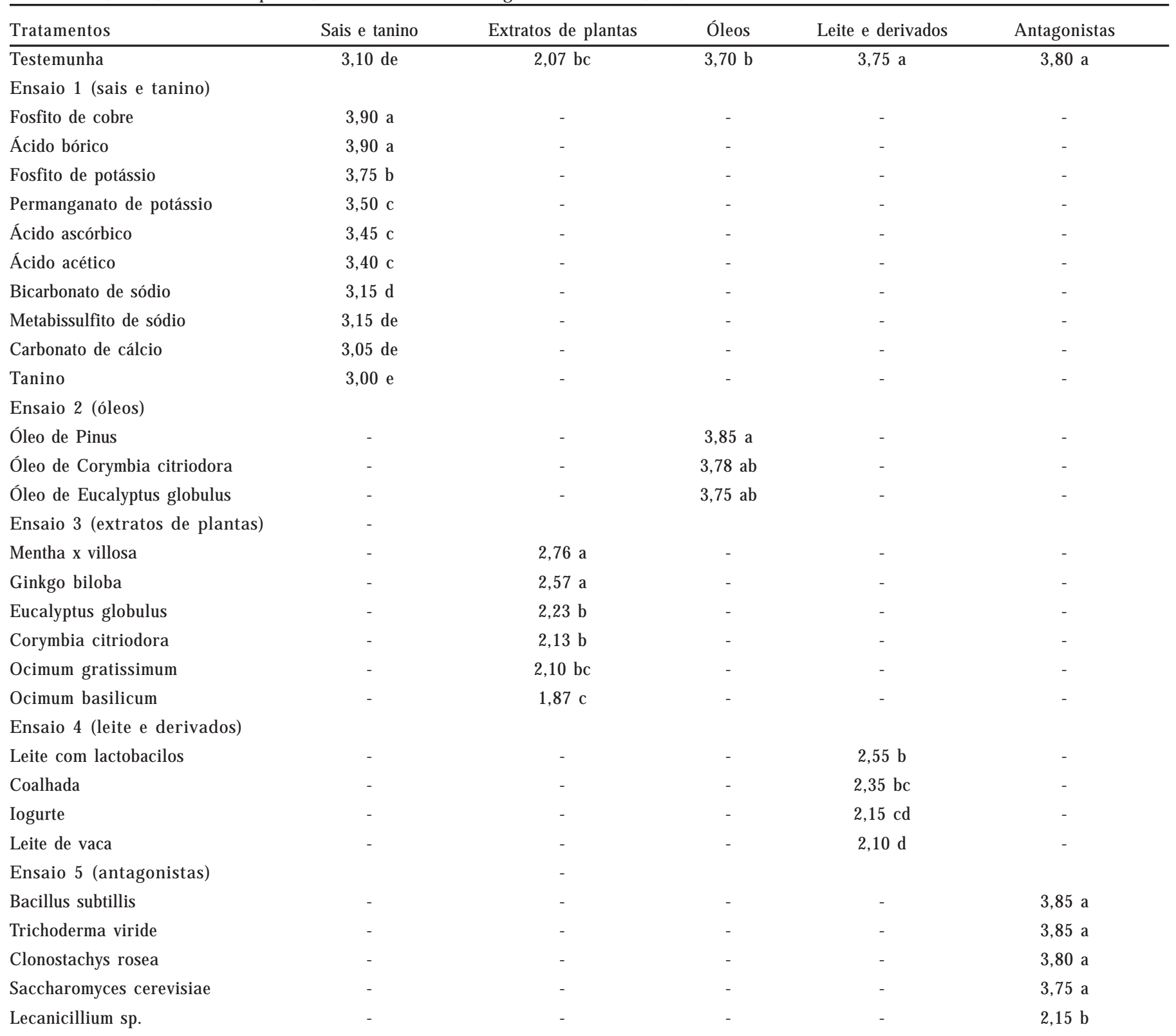

Severidade: 0 - ausência de sintomas a 4 - infecção muito severa. Valores representam a severidade final média de 20 mudas (repetições) nos ensaios com sais e tanino, óleos, leite e derivados e antagonistas e de 30 mudas para extratos de plantas, após 34 dias da inoculação natural com 0 idium sp. M édias seguidas pela mesma letra não diferem entre si pelo teste de Tukey ao nível de $5 \%$ de probabilidade.

\section{Antagonistas}

Os tratamentos com B. subtilis, T. viride, C. rosea e S. cerevisiae não diferiram estatisticamente da testemunha. Somente L ecanicillium sp. apresentou o menor valor de severidade, controlando $43 \%$ da doença e diferindo estatisticamente dos demais tratamentos. Por esse motivo, este microrganismo foi selecionado como eficiente.

\section{Comparativo entre produtos}

No ensaio de comparação entre os tratamentos mais eficientes dos ensaios anteriores foram observadas diferenças significativas dos produtos al ternativos testados em relação à testemunha. L eite de vaca e L ecanicillum sp. apresentaram valores médios de A A CPD de 37,16 e 43,07, respectivamente, inferiores à testemunha (parâmetro de ausência de controle), enquanto que piraclostrobina + epoxiconazol (parâmetro de controle) apresentou o menor valor de AA CPD médio $(5,57)$.

Observaram-se, também, diferenças no comportamento da progressão da doença (Figura 1). A testemunha apresentou o maior valor de severidade e o fungicida a base de piraclostrobina + epoxiconazol mostrou o menor val or de severidade da doença, durante todo 0 ensai 0 . No caso de L ecanicillium sp. houve uma resposta variável do efeito deste microrganismo sobre a progressão da severidade do oídio, verificando-se inclusive um decréscimo na quantidade de doença aos 8 dias após a inoculação. Tal fato pode ser decorrente de uma menor colonização por parte do patógeno ou de maior estímulo na ação do antagonismo. Para o leite de vaca, houve um crescimento 
uniforme da doença até os 15 dias da inoculação e dois períodos de pausa no desenvolvimento da doença (aos 15-18 dias e aos 22-27 dias após a inoculação).

0 leite de vaca é relatado como eficiente no controle do oídio em abobrinha, pepino e eucalipto $(4,15)$. N o presente estudo, houve um controle de $44 \%$ no ensai o com leite e derivados e de $36,5 \%$ no ensaio comparativo, no qual o fungicida piraclostrobina + epoxiconazol promoveu um controle de $92 \%$.

Conforme relatado por A Ifenas et al. (1), a aplicação de leite em concentrações entre ( 5 e 50 \%) em minicepas de eucalipto pode causar fitotoxidez e favorecer a incidência de fumagina, causada por Cladosporium spp. Devido à al ta infestação do oídio na casa-devegetação onde foram realizados os experimentos deste trabalho, utilizou-se a concentração de $20 \%$ de leite de vaca, onde também foi constatada a presença de fumagina, principalmente nas últimas avaliações.

A pesar do fungo Lecanicillium sp. ser indicado para o controle biológico de insetos, houve controle do oídio em 33,9\%. A principal ação deste antagonista sobre Oidium sp. deve ter sido por meio do hiperparasitismo (3).

No caso da recomendação de produtos al ternativos ao controle do oídio do eucalipto poder-se-iam indicar tanto o leite de vaca como 0 Lecanicillium sp. No caso do antagonista, o mercado de produtos biológicos ainda não possui volume suficiente para atender a demanda para o controle do oídio do eucalipto. Pela praticidade de obtenção e preparo para a aplicação em viveiros de mudas de eucalipto, recomendase 0 uso de leite de vaca cru, a exemplo do que existe na literatura nacional (6).

\section{AGRADECIMENTOS}

A gradecemos ao CN Pq pelo financiamento do projeto de pesquisa e pela cessão de bolsa de mestrado, à empresa T urfal pela cessão do isolado de Lecanicillium sp., à E mbrapa M eio A mbiente pela cessão do isolado de B. subtilis e à Embrapa U va e Vinho pela cessão dos isolados de T. viride e de $C$. rosea, sem o qual os estudos não seriam possíveis.

\section{REFERÊNCIASBIBLIOGRÁFICAS}

1. Alfenas, A. C.; Zauza, E. A. V.; M afia, R. G.; A ssis, T. F. de. Clonagem e doenças do eucalipto. Viçosa: UFV. 2004. 442 p.

2. A uer, C. G.; Grigoletti Junior., A.; Santos, A. F. dos. Oídio em eucaliptos no estado do Paraná. Fitopatologia Brasileira, Brasília, v. 24, supl., p. 264, 1999. (Resumo).

3. Benhamou, N. Potencial of the mycoparasite, Verticillium lecanii, to protect citrus fruit against Penicillium digitatum, the causal agent of green mold: a comparison with the effect of chitosan. Phytopathology, Saint Paul, v. 94, n. 7, p. 693-705. 2004. 4. Bettiol, W. Controle de doenças de plantas com agentes de con- trole biológico e outras tecnologias alternativas. In: CampanhoIa, C.; B ettiol, W. M étodos alternativos de controle fitossanitário. Jaguariúna: Embrapa M eio A mbiente, p. 191-215. 2003.

5. Bettiol, W. A stiarraga, B. D. Controle de Sphaerotheca fuliginea em abobrinha com resíduo da fermentação glutâmica do melaço e produto lácteo fermentado. Fitopatologia Brasileira, B rasília, v. 23, n. 4, p. 431-435, 1998.

6. Bettiol, W.; Ghini, R.; M orandi, M. A. B. Alguns métodos alternativos para o controle de doenças de plantas disponíveis no Brasil. In: Venezon, M.; Paula Júnior, T. J. de; Pallini, A. Controle alternativo de pragas e doenças. Viçosa: EPAMIG/CTZM, p. 163-183, 2005.

7. Bizi, R.M.; Grigoletti Junior, A.; A uer, C.G. Seleção de fungicidas para o controle alternativo do oídio do eucalipto. Boletim de Pesquisa Florestal, Colombo, v. 51, p. 100-107, 2005.

8. Brown, B. N.; Ferreira, F. A. Diseases during propagation of eucalypts. In: Keane, P. J.; Kile, G. A.; Podger, F. D.; Brown, B. N. Diseases and pathogens of eucalypts. Collingwood: CSIRO, p. 119-151, 2000.

9. Campanhola, C.; B ettiol, W. M étodos alter nativos de controle fitossanitário. Jaguariúna: Embrapa M eio A mbiente. 2003. $279 p$.

10. Krugner, T. L.; A uer, C. G. Doenças dos eucaliptos. In: K imati, H.; A morim, L.; Rezende, J. A. M.; Bergamim Filho, A .; Camargo, L. E. A. M anual de fitopatologia; doenças das plantas cultivadas. 4. ed, São Paulo: A gronômica Ceres, 2005. v. 2, p. 319-332.

11. Paz Lima, M. L.; Lopes, C. A.; Café Filho, A. C. Estabilidade da resistência de Capsicum spp. ao oídio em telado e casa de vegetação. Fitopatologia Brasileira, Brasília, v. 29, n. 5, p. 519-525, 2004.

12. Rech, C.; Um futuro promissor. Revista da madeira, Curitiba, p. 4, setembro, 2001. Edição especial.

13. Ruiz Castro, A. Plagas y enfermidades de la vid. Madrid, Instituto Nacional de Investigaciones A gronomicas, 1965. p. 382417.

14. Santos, A. F. dos; A uer, C. G.; Grigoletti Junior., A. Doenças do eucalipto no sul do Brasil: identificação e controle. Colombo: Embrapa Florestas, 2001. 20 p. (Embrapa Florestas. Circular Técnica, 45).

15. Santos, C. A. G.; Furtado, E. L.; Silva, S. A. Controle de Oidium sp. em mini-jardim clonal de eucalipto através de leite de vaca in natura. Summa Phytopathologica, Botucatu, v. 29, n. 1, p. 51. 2003.

16. Schwan-Estrada, K. R. F.; Stangarlin, J. R.; Cruz, M. E. da S. U so de extratos vegetais no controle de fungos fitopatogênicos. Revista Floresta, Curitiba, v. 30, n. 1/2, p. 129-137, 2000.

17. Schwan-Estrada, K. R. F. Potencial de extratos e óleos essenciais de vegetais como indutores de resistência plantas medicinais. In: Reunião Brasileira sobre indução de resistência em plantas contra fitopatógenos,1, 2002, São Pedro. Perspectivas para o século XXI. São Pedro: ESALQ/USP, 2002. p. 27-28.

18. Silva, J. de C.. A madeira do futuro. Revista da madeira, Curitiba, p. 4, setembro. 2001. Edição especial.

19. Silva, M. B. da; Rosa, M. B.; Brasileiro, B. G.; Almeida, V.; Silva, C. A . Desenvolvimento de produtos à base de extratos de plantas para o controle de doenças de plantas. In: Venezon, M.; Paula Júnior, T. J. de; Pallini, A. Controle alternativo de pragas e doenças. Viçosa: EPAMIG/CTZM, p. 221-246, 2005. 